\title{
Variation in phenology and overall performance traits can help to explain the plant invasion process amongst Mediterranean ecosystems
}

\author{
Irene Martín-Forés ${ }^{1,2^{*}}$, Miguel A. Casado², Isabel Castro ${ }^{3}$, Alejandro del Pozo ${ }^{4}$, \\ Marco A. Molina-Montenegro,6, José M. de Miguel2 $^{2}$, Belén Acosta-Gallo²
}

I Department of Biogeography and Global Change, National Museum of Natural Sciences, Spanish National Research Council (MNCN-CSIC), Cl José Gutierrez Abascal 2, 28006, Madrid, Spain 2 Ecology, Department of Biodiversity, Ecology and Evolution, Complutense University of Madrid, Cl José Antonio Nováis 2, 28040, Madrid, Spain 3 Department of Ecology, Autonomous University of Madrid, C/ Darwin 2, Ciudad Universitaria de Cantoblanco, 28049, Madrid, Spain 4 Centro de Mejoramiento Genético y Genómica Vegetal, Facultad de Ciencias Agrarias, Universidad de Talca, Avda. Lircay s/n, Talca, Chile $\mathbf{5}$ Centro de Estudios Avanzados en Zonas Áridas (CEAZA), Universidad Católica del Norte, Coquimbo, Chile 6 Centro de Ecología Molecular y Funcional, Universidad de Talca, Avda. Lircay s/n, Talca, Chile

Corresponding author: Irene Martín-Forés (imfores@mncn.csic.es)

Academic editor: T. Knight | Received 24 September 2018 | Accepted 30 November 2018 | Published 21 December 2018

Citation: Martín-Forés I, Casado MA, Castro I, del Pozo A, Molina-Montenegro MA, de Miguel JM, Acosta-Gallo B (2018) Variation in phenology and overall performance traits can help to explain the plant invasion process amongst Mediterranean ecosystems. NeoBiota 41: 67-89. https://doi.org/10.3897/neobiota.41.29965

\begin{abstract}
Plant traits such as phenological development, growth rate, stress tolerance and seeds production may play an important role in the process of acclimatisation to new environments for introduced plants. Experiments that distinguish phenotypic plasticity from ecotypic differentiation would allow an understanding of the role of plant traits in the invasion process. We quantified the variation in phenological and overall performance traits associated with the invasion process for three herbaceous species native to Spain and invasive to Chile (Trifolium glomeratum, Hypochaeris glabra and Leontodon saxatilis). We grew plants from native and exotic populations along rainfall gradients in outdoor common gardens, located in the native and the introduced ranges and measured plant survival, phenology (days to flowering), biomass and seed output. Days to flowering was positively correlated with precipitation of the origin population for T. glomeratum and the native populations of $H$. glabra, but this pattern was not adaptive, as it was not associated with an increase in performance traits of these species. Phenology may instead reflect ecotypic differentiation to the environmental conditions of the original populations. Comparison between ranges (i.e. performance in both common gardens) was only possible for L. saxatilis. This species showed little
\end{abstract}

Copyright Irene Martín-Forés et al. This is an open access article distributed under the terms of the Creative Commons Attribution License (CC BY 4.0), which permits unrestricted use, distribution, and reproduction in any medium, provided the original author and source are credited. 
variation in phenology and both native and exotic populations had higher fitness in the introduced range. This suggests that plasticity enhances invasiveness through increased propagule pressure in the novel environment. Our findings highlight the utility of common garden experiments in examining patterns of phenological and performance traits that relate to species invasiveness.

\section{Keywords}

Asteraceae, biological invasions, biomass, common garden, Hypochaeris glabra, invasiveness, Leontodon saxatilis, phenology, precipitation, range expansion, seed output, survival, Trifolium glomeratum

\section{Introduction}

Despite recently gaining attention and considerable resources having been invested into studying habitat invasibility and species invasiveness (Richardson and Pyšek 2006, Guo et al. 2015), understanding the role played by invasive plant traits in the process of acclimatisation to the novel conditions along the introduced range still remains a key knowledge gap in invasion biology (but see MacDougall and Turkington 2005, Molina-Montenegro et al. 2010, Moravcová et al. 2015). Some overall performance traits have been suggested to be crucial for plant invasiveness, such as plant growth rate, environmental tolerance, phenological development and seed production (Noble 1989, Pyšek and Richardson 2007, van Kleunen et al. 2010, Moravcová et al. 2015). In this sense, it has been shown that greater plant growth and seed output account for the invasiveness of many alien plant species (Grotkopp and Rejmánek 2007), where species producing a greater number of seeds increase their propagule pressure and hence, their chances for establishment. However, the role of plant phenology in biological invasion processes and species invasiveness has often been neglected despite considerable differences in phenological development between native and invasive species having already been pointed out (Wolkovich and Cleland 2011, Godoy and Levine 2014).

Plant invasiveness often involves rapid adaptive evolution and/or genetic drift. Thus, invasive plants often undergo phenotypic differentiation to cope with novel environments through a combination of two processes, phenotypic plasticity and ecotypic differentiation (Maron et al. 2004, 2007, Molina-Montenegro et al. 2013). Phenotypic plasticity is the ability of a plant genotype to modify its physiology/morphology in response to environmental conditions and has been indicated as a mechanism that can mediate the establishment and dispersal in the new area (Valladares et al. 2005, 2006, Rejmánek et al. 2005, Richards et al. 2006, Pyšek and Richardson 2007, Pichancourt and van Klinken 2012). However, plasticity is not necessarily adaptive (i.e. does not always improve fitness) and the role that it plays in invasion processes remains still unclear (but see Chambel et al. 2005). Ecotypic differentiation may occur for the invasive plant species in the introduced range through selection of the optimal phenotype that provides local adaptation in different geographic locations, leading to many genotypes adapting to particular environmental conditions and thus allowing increased fitness (Lande 2009, Molina-Montenegro et al. 2013, 2018a, Martín-Forés et al. 2017c, 2018). For example, in more humid environments, plant phenology can 
show a delay which a priori gives plants more time to invest in biomass production and display more dispersal units (Pérez-Ramos et al. 2010).

It is known that these two processes can occur very quickly for annual Mediterranean species (Cocks et al. 1982, Small and Lefkovich 1986, del Pozo et al. 2000) that have been expanded beyond their initial distribution centre. As a result, some functional traits are expected to be affected and result in enhanced environmental tolerance and/or up-take of resources (Molina-Montenegro et al. 2018b).

Mediterranean-type ecosystems worldwide are considered as biodiversity hotspots and therefore targets for conservation policies (Myers et al. 2000), but despite many conservation efforts, the frequency and intensity of biological invasions in Mediterranean ecosystems is still considerable (Arianoutsou et al. 2013, Martín-Forés et al. 2017a). In this sense, the Mediterranean climate-type region of central Chile constitutes an interesting natural lab for exploring variations in functional traits caused by these mechanisms. Associated with the Spanish conquest that took place in the $16^{\text {th }}$ century, many exotic species were accidentally introduced into Chile (Martín-Forés et al. 2012, 2017a) and became naturalised in the Mediterranean climate region of central Chile.

Previous studies centred in the Mediterranean-type region of central Chile have shown a combination of these mechanisms for some species. For instance, for the invasive Asteraceae Taraxacum officinale, both plasticity and ecotypic differentiation for various traits were found in relation to latitudinal (Molina-Montenegro and Naya 2012, Molina-Montenegro et al. 2013, 2018a) or altitudinal (Molina-Montenegro et al. 2012) gradients in Chile. Additionally, ecotypic differentiation along environmental gradients has been observed for phenological development of Medicago polymorpha in Chile (del Pozo et al. 2000, 2002a, 2002b). In relation to performance traits, two of the most common invasive species in Chile, the Asteraceae Leontodon saxatilis subsp. rothii and Hypochaeris glabra showed increased propagule pressure and longer distance dispersal for exotic populations and at the introduced range (Martín-Forés et al. 2017c, Martín-Forés et al. 2018).

In particular, this study focuses on three annual species that are native to Spain and invasive to Chile, being broadly distributed in both the native and the introduced ranges, far beyond the Mediterranean climate distribution (Martín-Forés et al. 2012, Casado et al. 2015, 2018; See Suppl. material 1: Figure S1 for detailed information). Here, we bring together and compare plasticity and ecotypic differentiation not only on performance traits but also on phenology of two representatives of the Asteraceae family, Leontodon saxatilis subsp. rothii and Hypochaeris glabra (Martín-Forés et al. 2017, Martín-Forés et al. 2018) and one of the Fabaceae family, Trifolium glomeratum that has been selected because of its importance as a fodder plant.

Since the introduction of these three species into Chile (according to the first record, no more than 120 years ago; Castro et al. 2005), they have encountered different abiotic and biotic conditions in the introduced range from those of their native range (i.e. edaphic and climate characteristics, photoperiod, land use patterns, livestock grazing) as well as community interactions such as competence, tolerance and facilitation 
processes (Martín-Forés et al. 2015, 2016, 2017b). Accordingly, studies carried out in both the native and the introduced range of a species have been highlighted as of especial importance because they constitute the most direct test of determinants of invasiveness (Williams et al. 2008, van Kleunen et al. 2010). Thus, the aim of this study was to compare variations in phenology and performance traits associated with the invasion process of $L$. saxatilis, H. glabra and T. glomeratum into Chile. We used seeds from five Spanish populations and five Chilean populations collected along rainfall gradients in both countries and we evaluated all the populations in two common gardens located in Madrid, Spain and Cauquenes, Chile, that is in the native and introduced range, respectively. We explored $i$ ) whether the geographic origin of the plant collections (hereafter populations) could explain differences in plant phenology and performance traits within the same common garden trial and ii) whether individuals of the three species responded through phenotypic plasticity to the different climatic conditions existing in the two common garden trials regardless their population. The native populations of the three species have been longer exposed to local environmental conditions in the native range than exotic populations in the introduced one; therefore they have had more time to develop local adaptation through ecotypic differentiation. Thus, we would expect Spanish populations to present greater ecotypic differentiation than Chilean ones; if so, the delay in phenology while increasing the amount of precipitation on the origin population would be stronger for Spanish populations. Likewise, if the delay in phenology turns out to be adaptive, plants will display greater biomass and seed output.

\section{Methods}

\section{Study area}

The study was conducted in grasslands of the Mediterranean regions of Spain and central Chile (typically called dehesas and espinales, respectively) used for extensive livestock grazing, especially sheep and cattle. These grasslands present slightly acidic soils and are adapted to Mediterranean-type climate, characterised by having scarce precipitation in summer (drought period from June to September in the Northern hemisphere and from December to February in the Southern hemisphere).

For the three species, we selected five Spanish native populations and five Chilean exotic populations representative of the rainfall gradient existing in the Mediterranean regions of both countries. In Chile, the five populations were located in the central region (from $32^{\circ} 31^{\prime}$ to $37^{\circ} 00^{\prime} \mathrm{S}$ and $70^{\circ} 46^{\prime}$ to $72^{\circ} 34^{\prime} \mathrm{W}$ ), with mean annual precipitation ranging from 300 to $1200 \mathrm{~mm}$ (Table 1; Suppl. material 2: Figure S2). In Spain, the five populations were located in the centre-west of the Iberian Peninsula (from $38^{\circ} 16^{\prime}$ to $39^{\circ} 33^{\prime} \mathrm{N}$ and from $5^{\circ} 23^{\prime}$ to $6^{\circ} 20^{\prime} \mathrm{W}$ ), with mean annual precipitation ranging from 450 to $950 \mathrm{~mm}$ (Table 1; Suppl. material 2: Figure S2). The total annual precipitation $(\mathrm{mm})$, mean annual temperature $\left({ }^{\circ} \mathrm{C}\right)$ and number of months with drought period or 
Table I. Geographic and climatic characteristics of the populations of Hypochaeris glabra, Trifolium glomeratum and Leontodon saxatilis. TMED is mean annual temperature; $\mathrm{P}$ is the annual precipitation and MWD is the number of months with drought period or water deficit per year.

\begin{tabular}{|c|c|c|c|c|c|c|c|c|}
\hline Country & Site & Code & Species collected & Latitude & Longitude & $\begin{array}{l}\text { TMED } \\
\left({ }^{\circ} \mathrm{C}\right)\end{array}$ & $\underset{(\mathbf{m m})}{\mathbf{P}}$ & MWD \\
\hline Chile & Runge & Ch1a & T. glomeratum & $33^{\circ} 00^{\prime} 25^{\prime \prime S}$ & $70^{\circ} 53^{\prime} 45^{\prime \prime} \mathrm{W}$ & 14.27 & 303 & 8 \\
\hline Chile & Catapilco & Ch1b & H. glabra & $32^{\circ} 35^{\prime} 53^{\prime \prime} \mathrm{S}$ & $71^{\circ} 18^{\prime} 50^{\prime \prime} \mathrm{W}$ & 16.19 & 352 & 8 \\
\hline Chile & Melipilla & Ch2a & H. glabra, T. glomeratum & $33^{\circ} 49^{\prime} 18^{\prime \prime} \mathrm{S}$ & $71^{\circ} 18^{\prime} 58^{\prime \prime W}$ & 17.00 & 412 & 8 \\
\hline Chile & Pumanque & $\mathrm{Ch} 2 \mathrm{~b}$ & L. saxatilis & $34^{\circ} 37^{\prime} 48^{\prime \prime} \mathrm{S}$ & $71^{\circ} 42^{\prime} 54^{\prime \prime W}$ & 15.01 & 719 & 5 \\
\hline Chile & Boldo & Ch3 & H. glabra, T. glomeratum, L. saxatilis & $35^{\circ} 58^{\prime} 52^{\prime \prime} \mathrm{S}$ & $72^{\circ} 13^{\prime} 38^{\prime \prime W}$ & 14.33 & 794 & 5 \\
\hline Chile & Quirihue & Ch4 & H. glabra, T. glomeratum, L. saxatilis & $36^{\circ} 15^{\prime} 20^{\prime \prime} \mathrm{S}$ & $72^{\circ} 32^{\prime} 58^{\prime \prime} \mathrm{W}$ & 13.14 & 972 & 5 \\
\hline Chile & Yumbel & Ch5 & H. glabra, T. glomeratum, L. saxatilis & $37^{\circ} 00^{\prime} 26^{\prime \prime S}$ & $72^{\circ} 34^{\prime} 01^{\prime \prime W}$ & 13.33 & 1168 & 4 \\
\hline Spain & Castuera & S1 & H. glabra, T. glomeratum, L. saxatilis & $38^{\circ} 46^{\prime} 20^{\prime \prime} \mathrm{N}$ & $5^{\circ} 34^{\prime} 48^{\prime \prime W}$ & 16.89 & 468 & 4 \\
\hline Spain & Fuente de Canto & S2 & H. glabra, T. glomeratum, L. saxatilis & $38^{\circ} 16^{\prime} 33^{\prime \prime} \mathrm{N}$ & $6^{\circ} 20^{\prime} 22^{\prime \prime W}$ & 15.81 & 572 & 4 \\
\hline Spain & Madroñera & S3 & H. glabra, T. glomeratum, L. saxatilis & $39^{\circ} 25^{\prime} 23^{\prime \prime} \mathrm{N}$ & $5^{\circ} 47^{\prime} 48 " \mathrm{~W}$ & 15.42 & 666 & 4 \\
\hline Spain & Ibor & S4 & H. glabra, T. glomeratum, L. saxatilis & $39^{\circ} 32^{\prime} 53^{\prime \prime} \mathrm{N}$ & $5^{\circ} 22^{\prime} 57^{\prime \prime} \mathrm{W}$ & 14.46 & 859 & 4 \\
\hline Spain & Logrosán & S5 & H. glabra, T. glomeratum, L. saxatilis & $39^{\circ} 21^{\prime} 28^{\prime \prime} \mathrm{N}$ & $5^{\circ} 25^{\prime} 04^{\prime \prime} \mathrm{W}$ & 16.17 & 913 & 3 \\
\hline
\end{tabular}

water deficit per year, an index calculated as the number of months in which monthly mean temperature is at least double the monthly precipitation, were determined for each population (Table 1). Climate variables were obtained from WorldClim (Hijmans et al. 2005), at a resolution of 30 arc-seconds.

Selected populations ideally contained the three species studied. Flower heads of $L$. saxatilis, H. glabra and T. glomeratum were collected from the five native (i.e. Spanish) and the five exotic (i.e. Chilean) populations in spring of 2010, at the end of flowering periods for most plants (i.e. May-June in Spain and October-November in Chile). Mature flower heads were randomly collected from 50 individuals of each species at each population; the distance between the individuals selected within each population was at least $1 \mathrm{~m}$ from each other and they were haphazardly distributed around an area of approximately one hectare (for detailed information about data collection for $L$. saxatilis and H. glabra, see Martín-Forés et al. 2017c, 2018, respectively).

\section{Common garden growing conditions}

Seeds from the 50 collected flower heads were pooled together. In each range, seeds randomly chosen from each population were germinated in petri dishes on to filter paper and irrigated every two days with $5 \mathrm{ml}$ of distilled water. In the case of $L$. saxatilis and $H$. glabra, peripheral fruits and unbaked fruits were respectively chosen for subsequent planting because of their greater success in pre-germination studies (see Martín-Forés et al. 2017c, 2018 for detailed information). In the case of T. glomeratum, seeds were previously scarified by immersing them in boiling water for 5 minutes; afterwards, they were inoculated with Rhizobium trifolii before transplanting the seedlings to the common garden to ensure nodulation and nitrogen fixation. 
When the radicles of plants $\left(\mathrm{F}_{2}\right)$ reached $5 \mathrm{~mm}$, seedlings were transplanted into subplots within two common garden trials, one located at the Faculty of Agronomy of the Polytechnic University of Madrid, Spain $\left(40^{\circ} 26^{\prime} \mathrm{N}, 3^{\circ} 44^{\prime} \mathrm{W} ; 600 \mathrm{~m}\right.$ a.s.l.; $15^{\circ} \mathrm{C}$ mean annual temperature; $484 \mathrm{~mm}$ mean annual precipitation) in the native range and the other one located in central Chile, at the Experimental Centre of Cauquenes-INIA, Chile (35 $58^{\prime} \mathrm{S}, 72^{\circ} 17^{\prime} \mathrm{W} ; 140 \mathrm{~m}$ a.s.l.; $14.4^{\circ} \mathrm{C}$; $748 \mathrm{~mm}$ mean annual precipitation), in the introduced range. The experiments were set outdoors under semi-controlled conditions where large herbivores were excluded. Planting was conducted directly in the soil when the rain period started, i.e. in June 2012 in Chile and October 2012 in Spain. For each species in the Spanish trial, 20 seedlings of each population were planted in subplots of $200 \times 50 \mathrm{~cm}$ after removing surface vegetation through ploughing; however, due to space limitations, in the Chilean trial, only ten seedlings of each population were planted and the subplots size was $100 \times 50 \mathrm{~cm}$. In both countries, the distance between plants was $20 \mathrm{~cm}$ and the separation between neighbouring subplots was $30 \mathrm{~cm}$. A complete randomised design was used with three replicated subplots per population. Thus, there was a total of 87 subplots within each site: 45 containing populations from Spain (three species $\times$ five populations $\times$ three replicates) and 42 containing populations from Chile (three species $\mathrm{x}$ five populations (four in the case of $L$. saxatilis) $\mathrm{x}$ three replicates). The total number of individuals planted in Chile was 870 and in Spain was 1740. The nontargeted surface vegetation was continuously removed over the experimental period by hand to ensure plants in both common gardens experienced similar levels of competition. No additional treatment, such as fertilisation, occurred in any of the common gardens.

\section{Functional traits}

The experiment lasted for 180 and 250 days at the Chilean and Spanish common gardens, respectively. At each common garden, weekly values of precipitation and daily values of mean temperature were obtained from the meteorological stations that were located closest to the experiments (i.e. Cauquenes INIA meteorological station: $35^{\circ} 57^{\prime} \mathrm{S}, 72^{\circ} 17^{\prime} \mathrm{W} ; 164 \mathrm{~m}$ a.s.l. in Chile and Madrid Ciudad Universitaria meteorological station: $40^{\circ} 27^{\prime} \mathrm{N}, 3^{\circ} 43^{\prime} \mathrm{W}$; $640 \mathrm{~m}$ a.s.l. in Spain; see graphs in Fig. 1 and the Suppl. material 3: Figure S3 for detailed meteorological data).

Plant survival and phenology were recorded three times a week from sowing to flowering and every two days from flowering to plant fructification. Plants that died prior to accomplishing fruit maturity were no longer employed for assessing performance traits, while plants that accomplished maturity were considered dead after reaching $75 \%$ senescence. Phenological observation included the date when each individual got the first floral bud and was used to calculate the days from planting to flowering.

The number of flower heads per plant was counted for every individual. Flower heads were collected after they had produced fruits but before the infructescence opened, to ensure we captured all seeds and avoided propagules spreading. The average number of fruits per flower head was calculated for each individual by averaging the number of 



Figure I. Kaplan-Meier survival curves for Leontodon saxatilis (a), Hypochaeris glabra (b) and Trifolium glomeratum (c) in trials at both the native (green line) and the introduced ranges (orange line). Daily medium temperature values $\left({ }^{\circ} \mathrm{C}\right)$ during the experiment are shown with a continuous brown line, while precipitation ( $\mathrm{mm} /$ week) is represented by blue bars for both the common garden at the introduced range (d) and the common garden at the native range (e).

fruits counted over five flower heads that were collected from each plant when it reached around $50 \%$ senescence. The total seed output per plant was estimated by multiplying the average number of fruits per flower head by the number of flower heads per plant.

Once each individual had reached around $75 \%$ senescence, plants were harvested. Flower heads were removed and then the vegetative part was oven-dried at $60{ }^{\circ} \mathrm{C}$ for 72 hours. Afterwards, aboveground dry biomass (hereafter biomass) was weighed.

Due to the high mortality rate of H. glabra and T. glomeratum in the Spanish trial, further comparisons of phenology and performance traits between ranges (common gardens) were only possible to assess for $L$. saxatilis.

\section{Data analyses}

All analyses were performed in R v 3.2.3 (R Core Team 2015). To check differences in survival rates associated with climatic conditions of both common gardens, the cumulative survivals of the three species, expressed by their Kaplan-Meier curves, were plotted taking into consideration the environmental conditions of each common garden. For each species, comparisons for populations of both countries of origins (Spanish vs. Chilean) between Kaplan-Meier curves from the time seedlings were sown were performed with the R package survival (Therneau 2015).

We used mixed effects models using the base stats package plus lme4 (Bates et al. 2014) to explore differences in phenological and performance traits of L. saxatilis, H. glabra and 
T. glomeratum associated with the country of origin of the populations. We considered the plant individual as the unit of analysis (L. saxatilis: $\mathrm{n}=340 ;$ H. glabra: $\mathrm{n}=186 ;$ T. glomeratum: $\mathrm{n}=268$ ). Models were fitted taking into account phenology (i.e. days to flowering), plant growth (i.e. dry aboveground biomass) and estimated seed output per plant as response variables. We used mixed effects models with a Gaussian error distribution for the three response variables. Fixed effects included the country of origin (Spain and Chile) and the precipitation on the population (as populations were selected along a rainfall gradient) for $H$. glabra and T. glomeratum. In the case of $L$. saxatilis, we also explored whether phenology and performance traits of this species varied between common gardens located in the native and in the introduced ranges; thus not only the previous fixed factors but also the range where the common garden was emplaced were included. The subplot where populations were planted in the common garden was included as the random effect nested within population. All the possible models, including origin and precipitation (and range in the case of L. saxatilis) as predictors (as well as their interactions), were computed.

We compared the possible models differing in the structure of fixed effects fitted by maximum likelihood. We calculated the Akaike Information Criterion corrected for small sample size (AICc). We selected the best-fit models (lowest AICc presenting differences in their AICc lower than 2; Burnham and Anderson 2002) employing the AICcmodavg package (Mazerolle 2015). The parsimony principle was applied on the subset of best models based on AICc and the model with the lowest number of parameters was chosen for subsequent analyses (Cox et al. 2006). Selected models were fitted by Restricted Maximum Likelihood and significant values for fixed effects were calculated with a type-III ANOVA analysis with the lmerTest package (Kuznetsova 2017). Model validation of the best-fit model was based on visually assessing the normality of residuals. To test over-dispersion, we checked that the residual deviance was lower than the residual degrees of freedom (Zuur et al. 2009).

In order to evaluate whether a delay in phenological development could entail an increase in plant performance, we also performed mixed-effects models for performance traits (biomass and seed output) in which we entered days to flowering as predictor, precipitation as co-variable and subplot where populations were planted in the common garden nested within the population as random effects. These models were performed by splitting the plant individuals by origin (i.e. Spanish and Chilean). Marginal $r$ coefficients of these relationships as well as of the relationships between precipitation and phenology and performance traits were obtained per country of origin employing the R package MuMIn (Barton 2018). Finally, outliers that exceeded three times the interquartile range were removed prior to analyses, which only occurred for $1.5 \%$ of cases.

\section{Results}

There were differences between the climatic conditions of both Mediterranean regions; rainfall gradient was broader and number of months with water deficit longer in Chile than in Spain (300-1200 mm vs. 450-950 mm and 4-8 months vs. 3-4 months, respectively; Table 1$)$. 
The cumulative survivals of the three species, expressed by their Kapplan-Meier curves, were clearly different at both ranges, being significantly lower in the native range (Spanish trial) than in the introduced range (Chilean trial) (Fig. 1a-c, Suppl. material 4: Figure S4). In the Spanish trial, H. glabra and T. glomeratum - and, to a lesser extent also L. saxatilis - showed an abrupt mortality after 100 days from planting, whereas in the Chilean trial, the cumulative survival remained high (around 90\%) until the end of the experiment. The high mortality in the native range could be related to the scarce precipitation during late autumn and winter (from 1 December to 22 March; see Fig. 1d-e and Suppl. material 3: Figure S3). Due to the high mortality of H. glabra (84\%) and T. glomeratum (94\%) in the Spanish common garden, the comparison of phenology and performance traits between ranges (common gardens) was only possible for $L$. saxatilis.

According to the generalised linear mixed-effects models, the factors that explained most of the variation of phenology and performance traits for different populations varied amongst species (Table 2). For $T$. glomeratum, both origin of and precipitation on the population had a significant effect on days to flowering, that being the phenological development was significantly longer for Spanish populations than for Chilean ones (days to flowering for Spanish populations: $142 \pm 3$; days to flowering for Chilean populations: $131 \pm 3$ ). The relationship between days to flowering and the precipitation on the population were significant, regardless of the country of ori-

Table 2. Model coefficients (and Wald-chi square) for the selection of linear models after applying the parsimony criterion on the subset of best models based on AICc, regarding the effects of the country of origin, annual precipitation on the populations (Precip) and range of the common garden on Leontodon saxatilis, Hypochaeris glabra and Trifolium glomeratum traits: days to flowering, biomass and estimated total seed output. Subplot nested within population was considered as random factor in every model. All were fitted to a Gaussian distribution. First factor level: Chile; second factor level: Spain.

\begin{tabular}{|c|c|c|c|c|c|c|c|c|c|}
\hline & \multicolumn{3}{|c|}{ L. saxatilis } & \multicolumn{3}{|c|}{ H. glabra } & \multicolumn{3}{|c|}{ T. glomeratum } \\
\hline & $\begin{array}{c}\text { Days to } \\
\text { flowering }\end{array}$ & Biomass & $\begin{array}{c}\text { Seed } \\
\text { Output }\end{array}$ & $\begin{array}{c}\text { Days to } \\
\text { flowering }\end{array}$ & Biomass & $\begin{array}{c}\text { Seed } \\
\text { Output }\end{array}$ & $\begin{array}{c}\text { Days to } \\
\text { flowering }\end{array}$ & Biomass & $\begin{array}{c}\text { Seed } \\
\text { Output }\end{array}$ \\
\hline \multirow[t]{2}{*}{ Intercept } & 106.50 & 56.45 & 13867.45 & 115.9 & 19.18 & 7522.9 & 116.5 & 8.78 & 5568.4 \\
\hline & $\left(42.20^{* * *}\right)$ & $\left(218.09^{* * *}\right)$ & $\left(16.35^{* * *}\right)$ & $\left(2038.6^{* * *}\right)$ & $\left(83.3^{* * *}\right)$ & $\left(37.6^{* * *}\right)$ & $\left(738.2^{* * *}\right)$ & $\left(109.7^{* * *}\right)$ & $\left(46.1^{* * *}\right)$ \\
\hline \multirow[t]{2}{*}{ Origin } & -1.77 & - & 12518.95 & 8.73 & 10.39 & 6262.4 & 11.7 & 2.78 & 3285.1 \\
\hline & $(0.01)$ & - & $\left(6.79^{* *}\right)$ & $\left(5.4^{*}\right)$ & $\left(10.6^{* *}\right)$ & $\left(11.5^{* * *}\right)$ & $\left(18.4^{* * *}\right)$ & $\left(5.4^{*}\right)$ & $\left(7.7^{* *}\right)$ \\
\hline \multirow[t]{2}{*}{ Precip } & 0.00 & -0.04 & -4.41 & 0.38 & - & - & 0.02 & - & - \\
\hline & $(0.07)$ & $\left(65.90^{* * *}\right)$ & (1.44) & $(0.03)$ & - & - & $\left(13.6^{* * *}\right)$ & - & - \\
\hline \multirow[t]{2}{*}{ Range } & 124.91 & -48.86 & -11406.30 & - & - & - & - & - & - \\
\hline & $\left(244.74^{* * *}\right)$ & $\left(107.38^{* * *}\right)$ & $\left(11.20^{* * *}\right)$ & - & - & - & - & - & - \\
\hline \multirow[t]{2}{*}{ Origin*Precip } & 0.01 & - & -13.51 & 14.10 & - & - & - & - & - \\
\hline & $(0.18)$ & - & $\left(5.52^{*}\right)$ & $\left(9.2^{* *}\right)$ & - & - & - & - & - \\
\hline \multirow[t]{2}{*}{ Origin*Range } & -75.57 & - & -10587.77 & - & - & - & - & - & - \\
\hline & $\left(43.45^{* * *}\right)$ & - & $\left(4.85^{*}\right)$ & - & - & - & - & - & - \\
\hline \multirow[t]{2}{*}{ Precip*Range } & -0.06 & 0.03 & 6.51 & - & - & - & - & - & - \\
\hline & $\left(56.55^{* * *}\right)$ & $\left(38.01^{* * *}\right)$ & (3.10) & - & - & - & - & - & - \\
\hline Origin*Precip* & 0.07 & - & 11.25 & - & - & - & - & - & - \\
\hline Range & $\left(26.38^{* * *}\right)$ & - & (3.71) & - & - & - & - & - & - \\
\hline
\end{tabular}





Figure 2. Relationships between annual precipitation on the populations and plant traits (days to flowering, aboveground dry vegetative biomass and seed output per plant) for Leontodon saxatilis (a), Hypochaeris glabra (b) and Trifolium glomeratum (c) evaluated in common garden conditions at the introduced range. Significant relationships are shown by discontinuous (Chilean populations) or continuous (Spanish populations) lines. More detailed results about performance traits of $L$. saxatilis and $H$. glabra are available in Martín-Forés et al. (2017c, 2018).

gin (Spanish populations: $\mathrm{r}=0.53 ; \mathrm{P}<0.05$; Chilean populations: $\mathrm{r}=0.28 ; \mathrm{P}<0.05$; Fig. 2) In the case of $H$. glabra, the country of origin and its interaction with precipitation had an effect on the days to flowering; there was a close and positive relationship between days to flowering and the precipitation on the population for the Spanish populations $(\mathrm{r}=0.69$; $\mathrm{P}<0.05)$ but not for the Chilean ones (Table 2; Fig. 2). For T. glomeratum and $\mathrm{H}$. glabra, differences in days to flowering between the most precocious populations (from the driest provenances) and the latest flowering ones (from the wetter provenances) were up to 27 days. For $L$. saxatilis, the interaction between range and origin (model coefficient for the interaction origin(Spanish)* range(native): $\mathrm{t}=-6.59 ; \mathrm{p}<0.001$ ) had a significant influence on phenology (i.e. days to flowering) in the native range, while the effect of precipitation on the population origin was only significant for Spanish populations grown in the native range (model coefficient for the interaction origin (Spanish) ${ }^{*}$ precipitation ${ }^{*}$ range(native): $\mathrm{t}=5.14 ; \mathrm{p}<0.001$; Table 2; Fig. 2). Contrary to what was expected, no significant relationships were found between days to flowering and both biomass and seed output $(\mathrm{P}>0.05)$ for any species considered, indicating that a longer time for development does not involve greater reproductive effort.

For T. glomeratum and $H$. glabra, the biomass was only determined by the country of origin, with significantly larger plants coming from native populations (T. glomeratum: 
Spanish populations: $11.8 \mathrm{~g} \pm 0.8 \mathrm{~g}$; Chilean populations: $8.7 \mathrm{~g} \pm 0.5 \mathrm{~g}$; H. glabra: Spanish populations: $33.3 \mathrm{~g} \pm 4.2 \mathrm{~g}$; Chilean populations: $19.5 \mathrm{~g} \pm 1.8 \mathrm{~g}$; Table 2; Fig. 2 ). However, for $L$. saxatilis, there was a negative relationship between biomass and precipitation regardless of the origin of the populations considered (Fig. 2).

Seed output displayed by $T$. glomeratum and H. glabra was only determined by the country of origin, with native populations displaying greater number of seeds ( $T$. glomeratum: Spanish populations: $8978 \pm 1106$; Chilean populations: $5525 \pm 320 ; H$. glabra: Seed output: Spanish populations: $14686 \pm 2142$; Chilean populations: 7500 \pm 1545; Table 2; Fig. 2). For L. saxatilis, there was a negative relationship between seed output of native populations and precipitation on the population (Fig. 2).

Common garden comparisons showed that all the studied parameters were mainly influenced by range. Hence, phenology was significantly shorter in the introduced range than in the native one; while biomass and seed output were significantly greater in the introduced range than in the native one (Fig. 3).

\section{Discussion}

The need to carry out comparative studies of native versus introduced populations in order to detect key aspects to explain the invasion success as those related with functional traits of invaders has been highlighted in the scientific literature (Bossdorf et al. 2005, Molina-Montenegro et al. 2010, 2011, Lemoine et al. 2016). In this sense, our study highlights the differences existing in performance traits and especially in plant phenology associated with the invasion process of three herbaceous plants native to Spain but invasive to Chile.

However, comparison between native and introduced ranges was only possible for L. saxatilis due to the high mortality of H. glabra and T. glomeratum in the Spanish common garden. The three species presented a similar survival curve in the introduced range, where the weather conditions during the common garden experiment were milder and more benign. In this sense, the high survival rate showed by $L$. saxatilis in the native range, regardless of the extreme weather conditions during the Spanish common garden experiment and its resilience after a major drought event (see Fig. 1) could itself constitute an indicator of the plasticity of this species. However, please note that our results regarding phenotypic plasticity should be carefully interpreted as we could not account for genetic distances between mother sources and inter-population gene flow.

The phenology of $L$. saxatilis was mainly influenced by range instead of by country of origin of the populations; thus days to flowering showed different responses for the same population (either native or exotic ones) under different environmental conditions (native vs. introduced range). The variation in L. saxatilis phenology between ranges reflects its great capacity to acclimatise to changing environmental conditions (Geng et al. 2007, Gratani 2014). The delay in time to flowering of both Chilean and Spanish populations in the native range (Spain) can be attributed to the lower temper- 
atures in autumn and spring and lower precipitation compared to the introduced range (Chile) (Fig. 1 and Suppl. material 3: Figure S3). It is known that higher temperatures (Bradley et al. 1999) and longer day length accelerates plant development in temperate species (Molina-Montenegro and Naya 2012) and differences in day length and night length become more extreme at higher latitude (Bradshaw and Holzapfel 2008). Thus, in Madrid (latitude $40^{\circ} 26^{\prime} \mathrm{N}$ ), the day length or photoperiod is shorter in autumn and winter, but longer in spring and summer than in Cauquenes (latitude $35^{\circ} 58^{\prime} \mathrm{S}$ ). These patterns in temperature and photoperiod gave rise to large differences in the length of the growing season observed between the native and the introduced range.

Changes in flowering phenology amongst different populations constitute an indicator of ecotypic differentiation to the environmental conditions of the provenances where populations originated. According to our findings, populations of $T$. glomeratum and $H$. glabra have mainly undergone variation in their phenology to acclimatise to the new environmental conditions. These species exhibited clear differences in their phenology associated with the country of origin of the populations. In the case of $T$. glomeratum, phenological development was shorter for populations (both native and exotic ones) originating in drier provenances and phenology became lengthened for populations originating in more humid provenances (Table 2; Fig. 3). In fact, similar results were reported by del Pozo et al. (2000, 2002a, 2002b) in another Fabaceae, Medicago polymorpha. Regarding H. glabra, a similar delay was observed in phenological development for Spanish populations originating in more humid provenances, but this trend was not observed for Chilean populations. The fact that exotic populations of T. glomeratum originating in more humid provenances showed a phenological delay in relation to those originating in drier provenances (although this was not shown for exotic populations of the two daisies) could be related with the time since introduction of the three invasive species in central Chile. The leguminous $M$. polymorpha and T. glomeratum were first recorded before 1799 and in 1897, respectively (Castro et al. 2005), so they had been naturalised in the introduced range for several decades, possibly with enough time to undergo acclimatisation. Following the same criteria, H. glabra, a species that was first recorded in Chile in 1905 (Fuentes et al. 2013), showed differences between native and exotic populations; nevertheless, Chilean populations did not show ecotypic differences amongst them. In contrast, $L$. saxatilis was first recorded in Chile in 1963, therefore it has had only a short time to undergo rapid evolution (Buswell et al. 2011) or to develop further strategies, relying mainly in plastic responses in its phenology and performance traits. However, the significant interactions between range, country of origin and precipitation found in L. saxatilis point to ecotypic differences for Spanish populations grown in the native range, where populations from drier provenances have shortened their period of phenological development.

In any case, contrary to what might be expected, the delay in phenology associated with the precipitation on the population showed by $T$. glomeratum and by the native populations of $H$. glabra was not adaptive sensu stricto as it did not increase the performance traits of these species. Therefore, this mechanism could allow populations to acclimatise to a wider environmental range (i.e. enhance their invasiveness via increas- 

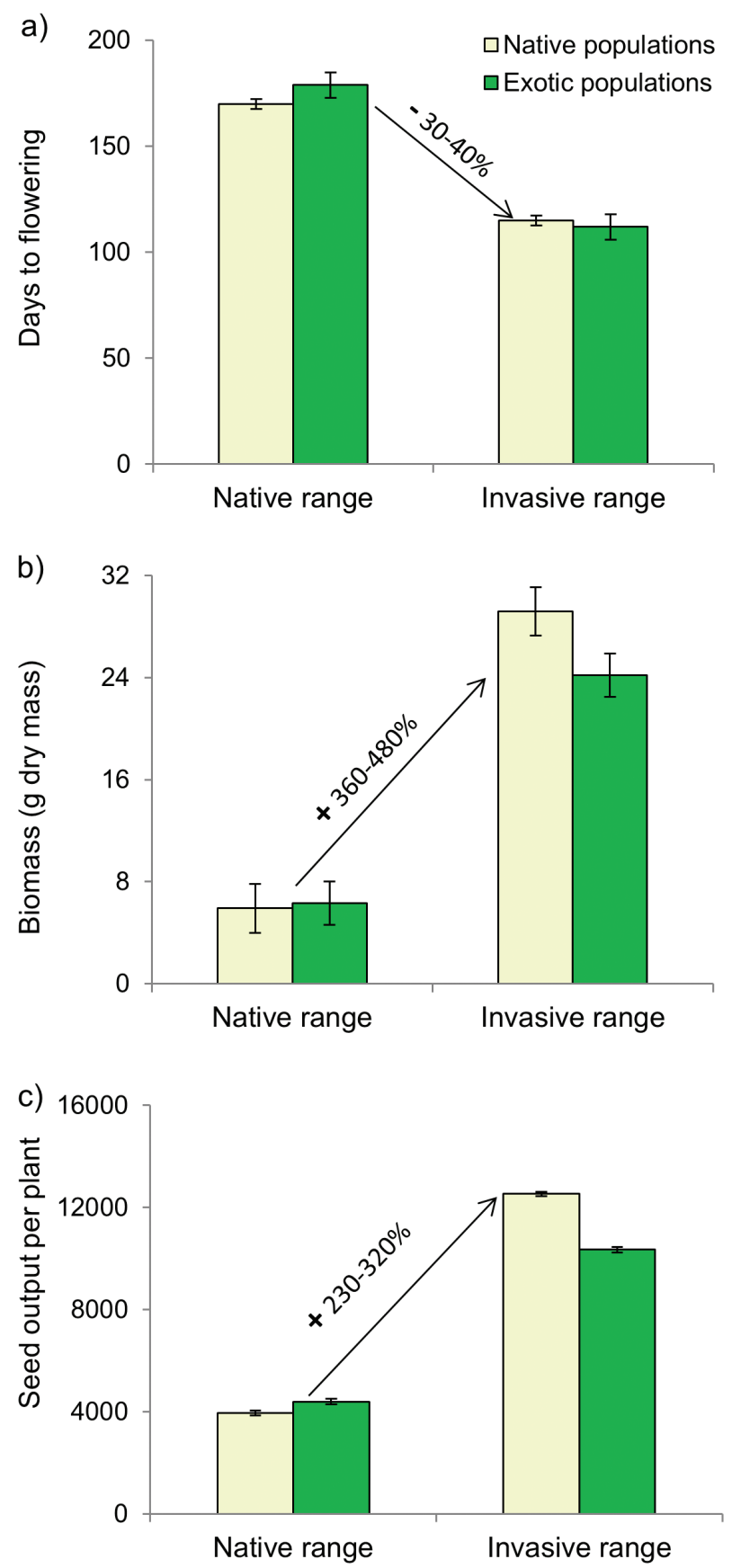

Figure 3. Comparisons between trials at the native and the introduced ranges for native and exotic populations of Leontodon saxatilis. Graphs show mean values and standard errors of days to flowering (a), biomass per plant (b) and seed output per plant (c) grouped by origin of the population. Percentages of variation between the native trial and the invasive one are also shown. The arrow indicates the direction of the colonisation process, from the source to the recipient region. 
ing range expansion) but it did not increase plant growth (i.e. biomass) nor propagule pressure (i.e. seed output did not result in enhanced days to flowering). Similarly, the delay in $L$. saxatilis phenological development at the native range was not invested in producing more biomass or displaying more seed output, probably due to the lower precipitation at the trial located in the native range compared to the trial at the introduced range. In the case of this species, no consistent patterns were found associated with the country of origin of the populations.

Regarding performance traits, T. glomeratum exhibited clear differences in their biomass and seed output displayed associated with the country of origin of the populations. Contrary to what we expected, exotic populations have not apparently undergone selection for traits that allowed them to outperform native populations of the same species; in fact, native populations displayed greater seed output when cultivated under common garden conditions in the introduced range (Table 2). The very same trend was observed for $H$. glabra and L. saxatilis. This can be related to the fact that native populations of the three species showed a much lower survival rate than exotic ones under the novel environmental conditions of the introduced range (see Suppl. material 4: Figure S4). Exotic populations of these species might have overcome greater hydric stress typical from the Mediterranean-type region of central Chile by evolving resistance mechanisms, (presumably costly) which in turn trade off against biomass and seed output. Performance traits for $L$. saxatilis were mainly influenced by range (see Martín-Forés et al. 2017c for further discussion); in this sense, the increase in biomass and seed output displayed by L. saxatilis in the introduced range compared to the native one, especially highlighted for native populations, reflects the invasive ability of this species, which shows an enhanced propagule pressure in the introduced range and the capacity to spread there. Our findings support the invasion patterns of $L$. saxatilis in central Chile, as it is the most frequent exotic species in this region (Martín-Forés et al. 2012) and it is widely distributed due to its invasiveness (Martín-Forés et al. 2015, 2017c). It is also an invader in other Mediterranean regions such as California and southern Australia (Groves et al. 2003, DiTomaso et al. 2007); thus, such a great plastic response might raise the potential of this species to spread in a global changing scenario (Guerin et al. 2014).

Their particular dispersal pathways could also influence these differences identified amongst species. For instance, Trifolium glomeratum has animal-dispersed fruits with low spreading capacity, probably needs to rely more on acclimatising to local conditions and adjusting its phenological development in relation to the precipitation on the origin of the population. On the contrary, both H. glabra and L. saxatilis have fruit dimorphism (i.e. heterocarpy; Baker and O'Dowd 1982, Brändel 2007); they are not only animal-dispersed but also undergo long distance dispersal events by wind (Martín-Forés et al. 2017c, 2018); in this case, a plastic response in survival, phenology and performance traits could be the most successful mechanism in the novel environment. However, further detailed research would be necessary to elucidate whether different mechanisms operate in the acclimatisation process to a new environment depending of the dispersal pathway of the species. 


\section{Conclusion}

Overall, the studied invasive species have evolved in their native range for millennia, while in their introduced range, they have only been present for few decades or over the last few centuries. Once they arrived to Chile, they spread and adapted to the whole Chilean climatic gradient. Trifolium glomeratum and $\mathrm{H}$. glabra mainly relied on ecotypic differentiation for plant phenology associated with the population origin while $L$. saxatilis mainly showed plasticity when growing in different ranges. However, changes in phenology were not reflected in greater biomass or seed output display but might rather be related to range expansion processes. Despite relying on different strategies, all these species have resulted as successful invaders in the Mediterranean Biome. All this highlights that, not only performance traits, but also phenology and plant survival are key traits that need to be targeted to account for species invasiveness and therefore to predict future invasions and control for existing ones.

\section{Acknowledgements}

We thank the Spanish Ministry of Science and Innovation for the financial support received to carry out this study (CGL2009-08718) and the grants REMEDINAL (S2013/MAE-2719 REMEDINAL3-Comunidad de Madrid) and SPONFOREST (BiodivERsA3-2015-58, PCIN-2016-055) and the Spanish Ministry of Education, Culture and Sport, because of the pre-doctoral FPU scholarship of the main author (AP2009-0518). We thank the State Meteorological Agency for providing meteorological data (AEMET, http://www.aemet.es/es/portada). We are especially grateful for the advice and suggestions provided by Greg Guerin. We would like to acknowledge Teresa Aravena, María Elena Díaz, Teresa Moreno Vicente, Marta Avilés, Devayana Valero and Ricardo Prentice for their support in phenological observations and Laura Sánchez-Jardón and Carlos Ovalle for field support. Likewise, we would like to acknowledge the whole INIA-Cauquenes Institution, in central Chile and the team from the Faculty of Agronomy of the Polytechnic University of Madrid, especially Daniel de la Torre Llorente.

\section{References}

Arianoutsou M, Delipetrou P, Vilà M, Dimitrakopoulos PG, Celesti-Grapow L, WardellJohnson G, Henderson L, Fuentes N, Ugarte-Mendes E, Rundel PW (2013) Comparative patterns of plant invasions in the Mediterranean Biome. PloS ONE 8: e79174. https://doi.org/10.1371/journal.pone.0079174

Aronson J, Kigel J, Shmida A, Klein J (1992) Adaptive phenology of desert and Mediterranean populations of annual plants grown with and without water stress. Oecologia 89: 17-26. https://doi.org/10.1007/BF00319010 
Aronson J, Kigel J, Shmida, A (1993) Reproductive allocation strategies in desert and Mediterranean populations of annual plants grown with and without water stress. Oecologia 93: 336-342. https://doi.org/10.1007/BF00317875

Aronson J, del Pozo A, Ovalle C, Avendańo J, Lavin A, Etienne M (1998) Land use changes and conflicts in Central Chile. In: Rundel PW, Montenegro G, Jaksic F (Eds) Landscape Disturbance and Biodiversity in Mediterranean Type Ecosystems. Springer, Berlin, 155168. https://doi.org/10.1007/978-3-662-03543-6_9

Arroyo MTK, Marticorena C, Matthei O, Cavieres LA (2000) Plant invasions in Chile: present patterns and future predictions. In: Mooney HA, Hobbs RJ (Eds) Invasive Species in a Changing World. Island, Washington, 395-421.

Baker A, O'Dowd DJ (1982) Effects of parent plant density on the production of achene types in the annual Hypochoeris glabra. Journal of Ecology 70: 201-215. https://doi. org/10.2307/2259873

Barton K(2018) MuMIn:Multi-Model Inference. https://CRAN.R-project.org/package=MuMIn. $\mathrm{R}$ package version 1.40 .4

Bates D, Maechler M, Bolker B, Walker S, Christensen RHB, Singmann H (2014) lme4: Linear mixed-effects models using Eigen and S4. 1-6. https://cran.r-project.org/package=lme4 [R package version 1]

Bossdorf O, Auge H, Lafuma L, Rogers WE, Siemann E, Prati D (2005) Phenotypic and genetic differentiation between native and introduced plant populations. Oecologia 144: 1-11. https://doi.org/10.1007/s00442-005-0070-z

Bradley NL, Leopold AC, Ross J, Huffaker W (1999) Phenological changes reflect climate change in Wisconsin. Proceedings of the National Academy of Science USA 96: 97019704. https://doi.org/10.1073/pnas.96.17.9701

Bradshaw WE, Holzapfel CM (2008) Genetic response to rapid climate change: it's seasonal timing that matters. Molecular Ecology 17: 157-166. https://doi.org/10.1111/j.1365294X.2007.03509.x

Brändel M (2007) Ecology of achene dimorphism in Leontodon saxatilis. Annals of Botany (London) 100: 1189-1197. https://doi.org/10.1093/aob/mcm214

Buswell JM, Moles AT, Hartley S (2011) Is rapid evolution common in introduced plant species? Journal of Ecology 99: 214-224. https://doi.org/10.1111/j.1365-2745.2010.01759.x

Burnham KP, Anderson DR (2002) Model selection and multimodel inference: A practical information-theoretic approach ( $2^{\text {nd }}$ edn). Springer-Verlag, New York.

Casado MA, Acosta-Gallo B, Sánchez-Jardón L, Martín-Forés I, Castro I, Ovalle C, del Pozo A, de Miguel JM (2015) Interactive effects of source and recipient habitats on plant invasions: distribution of exotic species in Chile. Diversity and Distributions 21: 609-619. https:// doi.org/10.1111/ddi.12326

Casado MA, Martín-Forés I, Castro I, de Miguel JM, Acosta-Gallo B (2018) Asymmetric flows and drivers of herbaceous plant invasion success among Mediterranean-climate regions. Scientific Reports 8:16834.

Castro SA, Figueroa JA, Muñoz-Schick M, Jaksic FM (2005) Minimum residence time, biogeographical origin, and life cycle as determinants of the geographical extent of naturalized plants in continental Chile. Diversity and Distributions 11: 183-191. https://doi. org/10.1111/j.1366-9516.2005.00145.x 
Chambel MR, Climent J, Alía R, Valladares F (2005) Phenotypic plasticity: a useful framework for understanding adaptation in forest species. Investigaciones Agrarias: Sistemas de Recursos Forestales 14: 334-344. https://doi.org/10.5424/srf/2005143-00924

Cocks PS, Craig AD, Kenyon RV (1982) Evolution of subterranean clover in South Australia. II. Change in genetic composition of a mixed population after 19 years' on a commercial farm. Australian Journal of Agriculture Research 33: 679-695. https://doi.org/10.1071/AR9820679

Cox GM, Gibbons JM, Wood ATA, Ramsden SJ, Crout NJM (2006) Towards the systematic simplification of mechanistic models. Ecological Modelling 198: 240-246. https://doi. org/10.1016/j.ecolmodel.2006.04.016

D’Antonio CM, Vitousek PM (1992) Biological invasions by exotic grasses, the grass/fire cycle, and the global change. Annual Review of Ecology and Systematic 23: 63-87. https://doi. org/10.1146/annurev.es.23.110192.000431

del Pozo A, Ovalle C, Aronson J, Avendaño J (2000) Developmental responses to temperature and photoperiod in ecotypes of Medicago polymorpha L. along an environmental gradient in central Chile. Annals of Botany 85: 809-814. https://doi.org/10.1006/anbo.2000.1141

del Pozo A, Ovalle C, Aronson J, Avendaño J (2002a) Ecotypic differentiation in Medicago polymorpha L. along an environmental gradient in central Chile. I. Phenology, biomass production and reproductive patterns. Plant Ecology 159: 119-130. https://doi. org/10.1023/A:1015506914038

del Pozo A, Ovalle C, Aronson J, Avendaño J (2002b) Ecotypic differentiation in Medicago polymorpha L. along an environmental gradient in central Chile. II. Winter growth as related to phenology and temperature regime. Plant Ecology 160: 53-59. https://doi. org/10.1023/A:1015884930876

del Pozo A, Ovalle C, Casado MA, Acosta B, De Miguel JM (2006) Effects of grazing intensity in grasslands of the Espinal of central Chile. Journal of Vegetation Science 17: 791-798. https://doi.org/10.1111/j.1654-1103.2006.tb02502.x

DiTomaso JM, Healy EA (2007) Weeds of California and Other Western States. Vol. 3488, UCANR Publications. Oakland, CA.

Dlugosch KM, Parker IM (2008) Founding events in species invasions: genetic variation, adaptive evolution, and the role of multiple introductions. Molecular Ecology 17: 431-449. https://doi.org/10.1111/j.1365-294X.2007.03538.x

Dukes JS, Mooney HA (1999) Does global change increase the success of biological invaders? Trends in Ecology and Evolution 14: 135-139. https://doi.org/10.1016/S0169-5347(98)01554-7

Ehrman T, Cocks PS (1990) Ecogeography of annual legumes in Syria: distribution patterns. Journal of Applied Ecology 27: 578-591. https://doi.org/10.2307/2404303

Ehrman T, Cocks PS (1996) Reproductive patterns in annual legume species on an aridity gradient. Vegetatio 122: 47-59. https://doi.org/10.1007/BF00052815

Figueroa JA, Castro SA, Marquet PA, Jaksic FM (2004) Exotic plant invasions to the Mediterranean region of Chile: causes, history and impacts. Revista Chilena de Historia Natural 77: 465-483. https://doi.org/10.4067/S0716-078X2004000300006

Fox GA (1989) Consequences of flowering-time variation in a desert annual: Adaptation and history. Ecology 70: 1294-1306. https://doi.org/10.2307/1938189

Fox GA (1990) Drought and the evolution of flowering time in desert annuals. American Journal of Botany 77: 1508-1518. https://doi.org/10.1002/j.1537-2197.1990.tb12563.x 
Funk JL (2008) Differences in plasticity between invasive and native plants from a low resource environment. Journal of Ecology 96: 1162-1173. https://doi.org/10.1111/j.13652745.2008.01435.x

Galen C, Shore JS, Deyoe H (1991) Ecotypic divergence in alpine Polemonium viscosum: genetic structure, quantitative variation and local adaptation. Evolution 45: 1218-1228.

Gea-Izquierdo G, Allen-Diaz B, Miguel AS, Canellas I (2010) How do trees affect spatiotemporal heterogeneity of nutrient cycling in Mediterranean annual grassland? Annals of Forest Science 67: 112. https://doi.org/10.1051/forest/2009091

Geng YP, Pan XY, Xu CY, Zhang WJ, Li B, Chen JK, Lu BR, Song ZP (2007) Phenotypic plasticity rather than locally adapted ecotypes allows the invasive alligator weed to colonize a wide range of habitats. Biological Invasions 9: 245-256. https://doi.org/10.1007/s10530006-9029-1

Godoy O, Levine JM (2014) Phenology effects on invasion success: insights from coupling field experiments to coexistence theory. Ecology 95: 726-736. https://doi.org/10.1890/13-1157.1

Gratani L (2014) Plant phenotypic plasticity in response to environmental factors. Advances in Botany 2014: e208747. http://doi.org/10.1155/2014/208747

Grotkopp E, Rejmánek M (2007) High seedling relative growth rate and specific leaf area are traits of invasive species: phylogenetically independent contrasts of woody angiosperms. American Journal of Botany 94: 526-532. https://doi.org/10.3732/ajb.94.4.526

Groves RH, Hosking JR, Batianoff GN, Cooke DA, Cowie ID, Johnson RW, Keighery GJ, Lepschi BJ, Mitchell AA, Moerkerk M, Randall RP, Rozefelds AC, Walsh NG, Waterhouse BM (2003) Weed categories for natural and agricultural ecosystem management. Bureau of Rural Sciences, Canberra. http://doi.org/10.1155/2014/208747

Guerin G, Martín-Forés I, Biffin E, Baruch Z, Breed MF, Christmas MJ, Cross HB, Lowe AJ (2014) Global change community ecology beyond species-sorting: a quantitative framework based on Mediterranean-biome examples. Global Ecology and Biogeography 23: 1062-1072. https://doi.org/10.1111/geb.12184

Guo Q, Fei S, Dukes JS, Oswalt CM, III BVI, Potter KM (2015) A unified approach for quantifying invasibility and degree of invasion. Ecology 96: 2613-2621. https://doi. org/10.1890/14-2172.1

Hijmans RJ, Cameron SE, Parra JL, Jones PG, Jarvis A (2005) Very high resolution interpolated climate surfaces for global land areas. International Journal of Climatology 25: 1965-1978. https://doi.org/10.1002/joc.1276

IBM Corp (2013) IBM SPSS Statistics for Windows, Version 22.0. IBM Corp, Armonk, NY.

Imbert E (1999) The effects of achene dimorphism on the dispersal in time and space in Crepis sancta (Asteraceae). Canadian Journal of Botany 77: 508-513. https://doi.org/10.1139/b99-011

Imbert E (2002) Ecological consequences and ontogeny of seed heteromorphism. Perspectives in Plant Ecology 5: 13-36. https://doi.org/10.1078/1433-8319-00021

Joffre R, Rambal S, Ratte P (1999) The dehesa system of southern Spain and Portugal as a natural ecosystem mimic. Agroforestry Systems 45: 57-79. https://doi. org/10.1023/A:1006259402496

Kuznetsova A (2017) lmerTest: Tests in Linear Mixed Effects Models. https:/CRAN.R-project. org/package=lmerTest [R package version 2.0-36] 
Lemoine NP, Burkepile DE, Parker JP (2016) Quantifying differences between native and introduced species. Trends in Ecology and Evolution 31: 372-381. https://doi.org/10.1016/j. tree.2016.02.008

Loi A, Howieson JG, Cocks PS, Caredda S (1993) The adaptation of Medicago polymorpha to a range of edaphic and environmental conditions: effect of temperature on growth, and acidity stress on nodulation and nod gene induction. Australia Journal of Agriculture Research 33: 25-30. https://doi.org/10.1071/EA9930025

MacDougall AS, Turkington R (2005) Are invasive species the drivers or passengers of change in degraded ecosystems? Ecology 86: 42-55. https://doi.org/10.1890/04-0669

Maron JL, Vilà M, Bommarco R, Elmendorf S, Beardsley P (2004) Rapid evolution of an invasive plant. Ecological Monographs 74: 261-280. https://doi.org/10.1890/03-4027

Maron JL, Elmendorf SC, Vilà M (2007) Contrasting plant physiological adaptation to climate in the native and introduced range of Hypericum perforatum. Evolution 61: 1912-1924. https://doi.org/10.1111/j.1558-5646.2007.00153.x

Martín-Forés I, Casado MA, Castro I, Ovalle C, del Pozo A, Acosta-Gallo B, Sánchez-Jardón L, de Miguel JM (2012) Flora of the Mediterranean basin in the Chilean espinales: evidence of colonization. Pastos 42: 135-158.

Martín-Forés I, Sánchez-Jardón L, Acosta-Gallo B, del Pozo A, Castro I, de Miguel JM, Ovalle C, Casado MA (2015) From Spain to Chile: environmental filters and success of herbaceous species in Mediterranean-climate regions. Biological Invasions 17: 1425-1438. https://doi.org/10.1007/s10530-014-0805-z

Martín-Forés I, Castro I, Acosta-Gallo B, del Pozo A, Sánchez-Jardón L, de Miguel JM, Ovalle C, Casado MA (2016) Alien plant species coexist over time with native ones in Chilean Mediterranean grasslands. Journal of Plant Ecology 9: 682-691. https://doi.org/10.1093/jpe/rtw043

Martín-Forés I (2017a) Exotic Plant Species in the Mediterranean Biome: A Reflection of Cultural and Historical Relationships. In: Fuerst-Bjeliš B (Ed.) Mediterranean Identities - Environment, Society, Culture. InTech Open, Croatia. 180-202. https://doi.org/10.5772/intechopen.69185

Martín-Forés I, Guerin GR, Lowe AJ (2017b) Weed abundance is positively correlated with native plant diversity in grasslands of southern Australia. PLoS ONE 12: e0178681. https:// doi.org/10.1371/journal.pone.0178681

Martín-Forés I, Avilés M, Acosta-Gallo B, Breed MF, del Pozo A, de Miguel JM, SánchezJardón L, Castro I, Ovalle C, Casado MA (2017c) Ecotypic differentiation and phenotypic plasticity combine to enhance the invasiveness of the most widespread daisy in Chile, Leontodon saxatilis. Scientific Reports 7: 1546. https://doi.org/10.1038/s41598-017-01457-1

Martín-Forés I, Acosta-Gallo B, Castro I, de Miguel JM, del Pozo A, Casado MA (2018) The invasiveness of Hypochaeris glabra (Asteraceae): Responses in morphological and reproductive traits for exotic populations. PLoS ONE 13: e0198849. https://doi.org/10.1371/ journal.pone.0198849

Mazerolle MJ (2013) AICcmodavg: Model selection and multimodel inference based on (Q) AIC(c). http://cran.r-project.org/web/packages/AICcmodavg/index.html [R package 1.35]

McDowell SCL (2002) Photosynthetic characteristics of invasive and non-invasive species of Rubus (Rosaceae). American Journal of Botany 89: 1431-1438. https://doi.org/10.3732/ ajb.89.9.1431 
Molina-Montenegro MA, Atala C, Gianoli E (2010) Phenotypic plasticity and performance of Taraxacum officinale (dandelion) in habitats of contrasting environmental heterogeneity. Biological Invasions 12: 2277-2284. https://doi.org/10.1007/s10530-009-9638-6

Molina-Montenegro MA, Naya DE (2012) Latitudinal patterns in phenotypic plasticity and fitness-related traits: assessing the climatic variability hypothesis $(\mathrm{CVH})$ with an invasive plant species. PLoS ONE 7: e47620. https://doi.org/10.1371/journal.pone.0047620

Molina-Montenegro MA, Peñuelas J, Munné-Bosch S, Sardans J (2012) Higher plasticity in ecophysiological traits enhances the performance and invasion success of Taraxacum officinale (dandelion) in alpine environments. Biological Invasions 14: 21-33. https://doi. org/10.1007/s10530-011-0055-2

Molina-Montenegro MA, Palma-Rojas C, Alcayaga-Olivares Y, Oses R, Corcuera LJ, Cavieres LA, Gianoli E (2013) Ecophysiological plasticity and local differentiation help explain the invasion success of Taraxacum officinale (dandelion) in South America. Ecography 36: 718-730. https://doi.org/10.1111/j.1600-0587.2012.07758.x

Molina-Montenegro MA, Acuña-Rodríguez IS, Flores TSM, Hereme R, Lafón A, Atala C, Torres-Díaz C. (2018a) Is the success of plant invasions the result of rapid adaptive Evolution in Seed Traits? Evidence from a latitudinal rainfall gradient. Frontiers in Plant Science 9: 208. https://doi.org/10.3389/fpls.2018.00208

Molina-Montenegro MA, del Pozo A, Gianoli E (2018b) Ecophysiological basis of the Jackand-Master strategy: Taraxacum officinale (dandelion) as an example of a successful invader. Journal of Plant Ecology 11: 147-157.

Moravcová L, Pyšek P, Jarošík V, Pergl J (2015) Getting the right traits: reproductive and dispersal characteristics predict the invasiveness of herbaceous plant species. PloS One 10: e0123634. https://doi.org/10.1371/journal.pone.0123634

Myers N, Mittermeier RA, Mittermeier CG, Da Fonseca GA, Kent J (2000) Biodiversity hotspots for conservation priorities. Nature 403: 853-858. https://doi.org/10.1038/35002501

Neuffer B (1990) Ecotype differentiation in Capsella. Vegetatio 89: 165-171. https://doi. org/10.1007/BF00032168

Noble IR (1989) Attributes of invaders and the invading process: terrestrial and vascular plants in Biological invasions: a global perspective. Wiley, Chichester, 301-313.

Ovalle C, Aronson J, del Pozo A, Avendaño J (1990) The espinal: agroforestry systems of the Mediterranean-type climate region of Chile. Agroforestry Systems 10: 213-239. https:// doi.org/10.1007/BF00122913

Ovalle C, Del Pozo A, Casado MA, Acosta B, De Miguel JM (2006) Consequences of landscape heterogeneity on grassland diversity and productivity in the espinal agroforestry system of central Chile. Landscape Ecology 21: 585-594. https://doi.org/10.1007/s10980-005-3498-y

Pérez-Ramos IM, Ourcival JM, Limousin JM, Rambal S (2010) Mast seeding under increasing drought: results from a long-term data set and from a rainfall exclusion experiment. Ecology 91: 3057-3068. https://doi.org/10.1890/09-2313.1

Piano E, Pecetti L, Carroni AM (1996) Climatic adaptation in subterranean clover populations. Euphytica 92: 39-44. https://doi.org/10.1007/BF00022826

Pichancourt JB, van Klinken RD (2012) Phenotypic plasticity influences the size, shape and dynamics of the geographic distribution of an invasive plant. PLoS ONE 7: e32323. https://doi.org/10.1371/journal.pone.0032323 
Pineda FD, Montalvo J (1995) Dehesa systems in the western Mediterranean. In: Halladay P, Golmour DA (Eds) Conserving biodiversity outside protected areas. IUCN, Cambridge, 107-122.

Pyšek P, Richardson DM (2007) Traits associated with invasiveness in alien plants: where do we stand? In: Nentwig W (Ed.) Biological Invasions, Ecological Studies 193. Springer, Berlin and Heidelberg, 97-126. https://doi.org/10.1007/978-3-540-36920-2_7

R Core Team (2015) R: A language and environment for statistical computing. R Foundation for Statistical Computing, Vienna. https://www.R-project.org/

Rejmánek M, Richardson DM, Higgins SI, Pitcairn MJ, Grotkopp E (2005) Ecology of invasive plants: state of the art. In: Mooney HA, Mack RN, McNeely JA, Neville LE, Schei PJ, Waage JK (Eds) Invasive Alien Species a New Synthesis. Island Press, Washington DC, $104-161$.

Richards CL, Bossdorf O, Muth NZ, Gurevitch J, Pigliucci M (2006) Jack of all trades, master of some? On the role of phenotypic plasticity in plant invasions. Ecology Letters 9: 981-993. https://doi.org/10.1111/j.1461-0248.2006.00950.x

Richardson DM, Pyšek P (2006) Plant invasions: merging the concepts of species invasiveness and community invasibility. Progress in Physical Geography 30: 409-431. https://doi. org/10.1191/0309133306pp490pr

Richardson DM, Pyšek P, Rejmánek M, Barbour MG, Panetta FD, West CJ (2000) Naturalization and invasion of alien plants: Concepts and definitions. Diversity and Distributions 6: 93-107. https://doi.org/10.1046/j.1472-4642.2000.00083.x

Sexton JP, McKay JK, Sala A (2002) Plasticity and genetic diversity may allow saltcedar to invade cold climates in North America. Ecological Applications 12: 1652-1660. https://doi. org/10.1890/1051-0761(2002)012[1652:PAGDMA]2.0.CO;2

Simberloff D, Martin J-L, Genovesi P, Maris V, Wardle DA, Aronson J, Courchamp F, Galil B, García-Berthou E, Pascal M, Pyšek P, Sousa R, Tabacchi E, Vilà M (2013) Impacts of biological invasions: what's what and the way forward. Trends in Ecology and Evolution 28: 58-66. https://doi.org/10.1016/j.tree.2012.07.013

Small E, Lefkovich LP (1986) Relationships among morphology, geography and infertility in Medicago. Canadian Journal of Botany 11: 41-76.

Therneau T (2015) Survival: A Package for Survival Analysis in S. version 2.38. https:// CRAN.R-project.org/package=survival

Valladares F, Dobarro I, Sánchez-Gómez D, Pearcy RW (2005) Photoinhibition and drought in Mediterranean woody saplings: scaling effects and interactions in sun and shade phenotypes. Journal of Experimental Botany 56: 483-494. https://doi.org/10.1093/jxb/eri037

Valladares F, Sánchez-Gómez D, Zavala MA (2006) Quantitative estimation of phenotypic plasticity: bridging the gap between the evolutionary concept and its ecological applications. Journal of ecology 94: 1103-1116. https://doi.org/10.1111/j.1365-2745.2006.01176.x

van Kleunen M, Weber E, Fischer M (2010) A meta-analysis of trait differences between invasive and non-invasive plant species. Ecology Letters 13: 235-245. https://doi.org/10.1111/ j.1461-0248.2009.01418.x

Williams JL, Auge H, Maron JL (2008) Different gardens, different results: native and introduced populations exhibit contrasting phenotypes across common gardens. Oecologia 157: 239-248. https://doi.org/10.1007/s00442-008-1075-1 
Wolkovich EM, Cleland EE (2011) The phenology of plant invasions: a community ecology perspective. Frontiers in Ecology and the Environment 9: 287-294. https://doi. org/10.1890/100033

Zuur AF, Ieno EN, Walker NJ, Saveliev AA, Smith GM (2009) Mixed effects models and extensions in ecology with R. Statistics for Biology and Health. Springer-Verlag, New York, USA. https://doi.org/10.1007/978-0-387-87458-6

\section{Supplementary material I}

\section{Figure S1}

Authors: Irene Martín-Forés, Miguel A. Casado, Isabel Castro, Alejandro del Pozo, Marco A. Molina-Montenegro, José M. de Miguel, Belén Acosta-Gallo

Data type: occurrence

Explanation note: Distribution of Leontodon saxatilis, Hypochaeris glabra and Trifolium glomeratum in both the native (Spain) and the introduced (Chile) ranges.

Copyright notice: This dataset is made available under the Open Database License (http://opendatacommons.org/licenses/odbl/1.0/). The Open Database License $(\mathrm{ODbL})$ is a license agreement intended to allow users to freely share, modify, and use this Dataset while maintaining this same freedom for others, provided that the original source and author(s) are credited.

Link: https://doi.org/10.3897/neobiota.41.29965.suppl1

\section{Supplementary material 2}

\section{Figure S2}

Authors: Irene Martín-Forés, Miguel A. Casado, Isabel Castro, Alejandro del Pozo, Marco A. Molina-Montenegro, José M. de Miguel, Belén Acosta-Gallo

Data type: occurrence

Explanation note: Map of the studied areas of Mediterranean grasslands in Spain and Chile, including populations sampled following a rainfall gradient (see Table 1). The location of the common gardens is shown (x). This figure has been adapted from Martín-Forés et al. (2015, 2018).

Copyright notice: This dataset is made available under the Open Database License (http://opendatacommons.org/licenses/odbl/1.0/). The Open Database License $(\mathrm{ODbL})$ is a license agreement intended to allow users to freely share, modify, and use this Dataset while maintaining this same freedom for others, provided that the original source and author(s) are credited.

Link: https://doi.org/10.3897/neobiota.41.29965.suppl2 


\section{Supplementary material 3}

\section{Figure S3}

Authors: Irene Martín-Forés, Miguel A. Casado, Isabel Castro, Alejandro del Pozo, Marco A. Molina-Montenegro, José M. de Miguel, Belén Acosta-Gallo

Data type: species data

Explanation note: Daily maximum and minimum temperatures (A and $B)$ and precipitation (C, D) at Cauquenes, Chile (A, C) and Madrid, Spain (B, D). Data are from 1 January - 31 December 2011 in Chile and 1 July 2011 - 30 June 2012 in Spain. The arrows indicate transplanting dates.

Copyright notice: This dataset is made available under the Open Database License (http://opendatacommons.org/licenses/odbl/1.0/). The Open Database License $(\mathrm{ODbL})$ is a license agreement intended to allow users to freely share, modify, and use this Dataset while maintaining this same freedom for others, provided that the original source and author(s) are credited.

Link: https://doi.org/10.3897/neobiota.41.29965.suppl3

\section{Supplementary material 4}

\section{Figure S4}

Authors: Irene Martín-Forés, Miguel A. Casado, Isabel Castro, Alejandro del Pozo, Marco A. Molina-Montenegro, José M. de Miguel, Belén Acosta-Gallo

Data type: statistical data

Explanation note: Tree diagrams for Leontodon saxatilis, Hypochaeris glabra and Trifolium glomeratum showing significant differences in survival curves. Each diagram represents the comparison of Kaplan-Meyer curves considering common garden range (first level: introduced vs native), country of origin (second level: Chile vs Spain), and populations (third level: nomenclature as in Table 1). For each population the percentage of survival is shown and the lowercase letters indicate similar groups amongst populations.

Copyright notice: This dataset is made available under the Open Database License (http://opendatacommons.org/licenses/odbl/1.0/). The Open Database License $(\mathrm{ODbL})$ is a license agreement intended to allow users to freely share, modify, and use this Dataset while maintaining this same freedom for others, provided that the original source and author(s) are credited.

Link: https://doi.org/10.3897/neobiota.41.29965.suppl4 